\title{
A strategic framework for selecting adverse events in healthcare for investigation to improve patient safety
}

\author{
Author: Athar Ali Tajik, MD* \\ *The Norwegian Healthcare Investigation Board, Norway \\ E-mail: athar.ali.tajik@gmail.com
}

\section{Abstract}

\begin{abstract}
Aims
This paper aims to address the research question: What is an effective framework to strategically select nationally reported serious adverse events in healthcare for investigation to improve patient safety?

\section{Background}

The healthcare system is globally under strain due to an aging population with increasing comorbidities. Serious adverse events remain a consistent challenge. Patient safety can be improved by investigating cases and addressing underlying systemic risks. However, due to resource limitations, only a limited number of cases can be investigated. This necessitates a strategic selection of cases with the greatest potential for improving patient safety. This paper aims to develop a theoretical framework that identifies the key strategic issues that should be addressed when setting up a new national healthcare safety investigative body to select adverse events for investigation.
\end{abstract}

\section{Methods}

This study will primarily draw on semi-structured interviews with senior stakeholders in key healthcare regulatory agencies in Norway. For comparative purposes, a stakeholder from a key United Kingdom healthcare agency was also interviewed. The interview template is developed based on insights from a literature review and develop existing safety frameworks such as the Framework for Managing Risk. The paper also draws on selected tools from Strategy Management.

\section{Results}

A novel theoretical framework was developed to help set up case selection mechanism in a new national investigative body. The framework consists of four strategic themes that should be considered both sequentially and cyclically. Within each theme several key policy questions were identified.

(1) Governance: role and powers, independence, and stakeholder engagement

(2) Monitoring risk: adverse events, quality indicators, and unexplained variation

(3) Strategic portfolio: broad coverage, vulnerable groups, and underreporting

(4) Individual case selection: outcome, systemic risk, and learning potential

\section{Conclusions}

Policy makers should carefully consider the themes and questions in the proposed theoretical framework when setting up a new national safety investigative agency. In turn, this can ensure that the implemented selection mechanism identifies cases with the greatest potential to improve patient safety. 


\section{Table of contents}

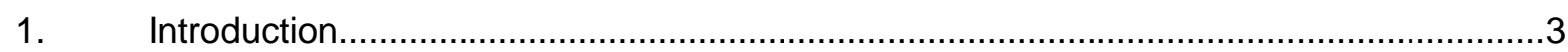

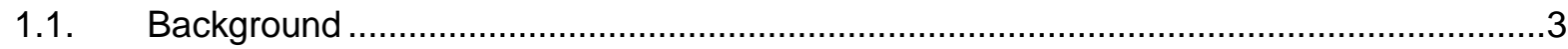

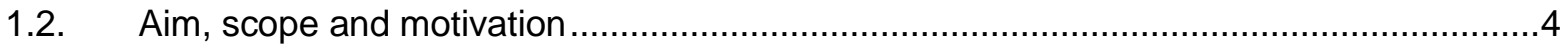

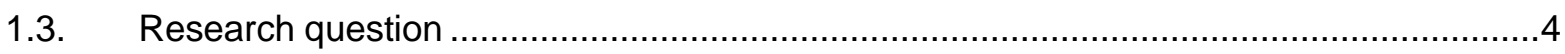

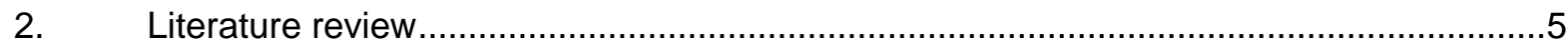

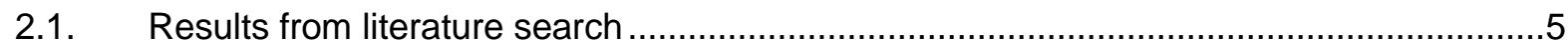

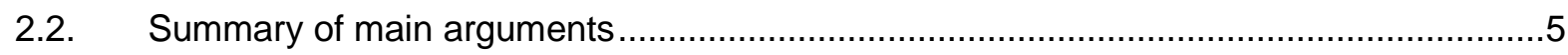

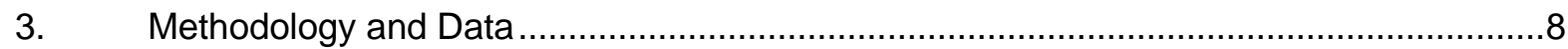

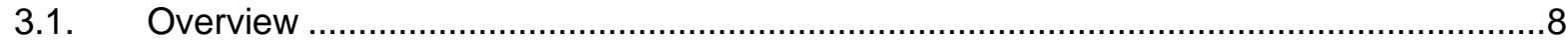

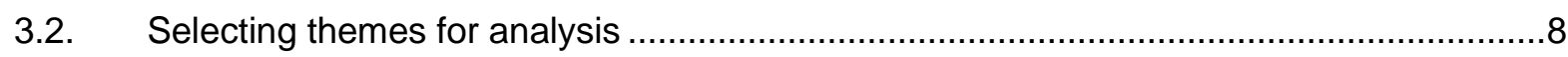

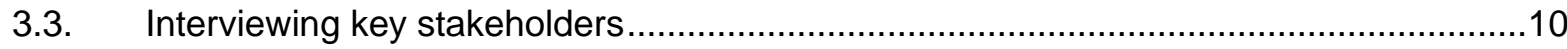

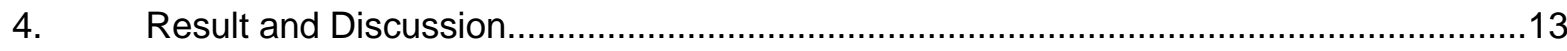

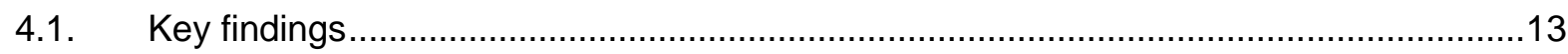

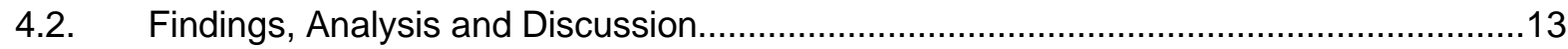

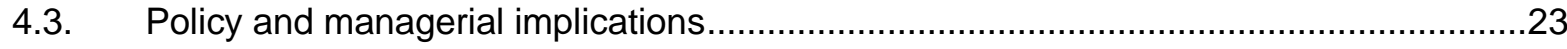

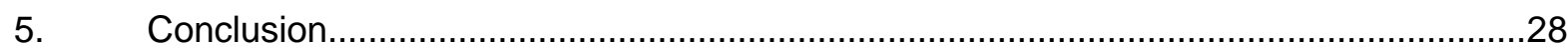

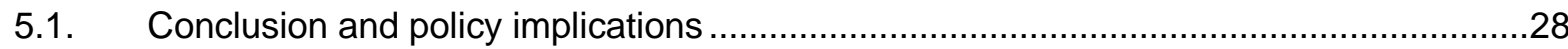

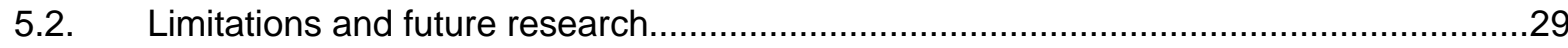

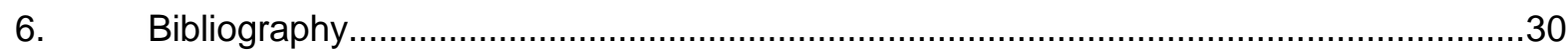

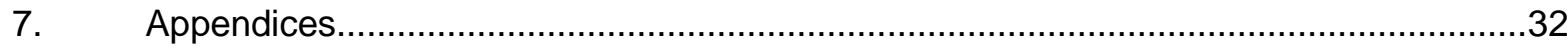

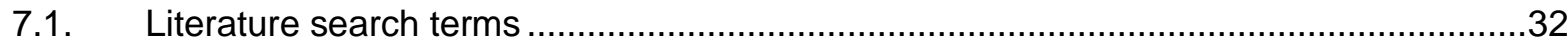




\section{Introduction}

\subsection{Background}

The healthcare system across the world is under increasing strain due to a rapidly aging population with more comorbidities. In many developed countries, the segment of the population aged 65 and above will nearly double going forward towards 2060 ("Population Reference Bureau (US): Fact Sheet," 2019; "Norwegian Statistical Bureau: A historic change," 2020). Simultaneously, we are facing a dramatic technological shift with increasing use of technology, personalized medicine, big data analysis and machine learning/artificial intelligence to improve healthcare delivery (Mitchell and Kan, 2019).

Healthcare remains a high-risk endeavour and serious adverse events are a consistent challenge. In Norway, there are several thousands of reports of serious adverse events and patient safety concerns annually ("Norwegian Health Supervision Board: Annual report," 2020). Indeed, even after several years of national efforts, adverse events may occur in near $12 \%$ of all patient hospital admissions ("The Norwegian Health Directorate: Patient Safety Programme," 2021). Data is lacking from the primary health sector and there is likely considerable underreporting.

Consequently, several countries, including Norway and the United Kingdom have implemented national bodies with the mandate to investigate serious adverse events with the aim to improve patient safety without assigning blame or liability. This includes the Healthcare Safety Investigation Branch (HSIB) in the UK and the Norwegian Healthcare Investigation Board (NHIB) (Wiig and Macrae, 2018). However, both are relatively young organizations and operate in a complex regulatory landscape interacting with other national health bodies.

There is considerable potential for improving quality, safety, and efficiency by investigating cases of serious adverse event. However, given the large volume of reported cases, most national healthcare safety investigative bodies only have resources to investigate a limited number of cases. This task is further complicated by the overlapping mandates and various approaches of other government and local authorities working to improve national patient safety. Indeed, a national health safety investigative body's case selection mechanism must be viewed in a larger context including external governance structures. Consequently, a strategic approach is needed when setting up a new health investigative body and its mechanism for selecting cases for investigation.

In the view of this author, and as can be surmised from the literature search, there is a gap in current knowledge when it comes to tools that can help policymakers address the strategic issues when setting up a new investigative body with a mechanism for case selection to maximize improvement in quality and safety. This paper therefore aims to develop a theoretical framework with a set of strategic questions that can help policy makers navigate these issues more efficiently. 


\subsection{Aim, scope and motivation}

There is currently limited experience on how to set up effective governance structures and case selection mechanisms that are robust enough to reliably identify cases that have the greatest potential to improve overall quality of care and patient safety. Indeed, a key challenge is that relevant investigative bodies exist in complex regulatory landscape and are part of a larger national patient safety effort.

Existing government agencies organizations in Norway and the UK have already had a couple of years to garner experiences and may serve as useful examples.

It is also important to note that the selection mechanisms should be adapted to local needs, taking into consideration socio-economic factors, the regulatory as well as the health risk landscape. Ultimately, selection of adverse events for investigation should form part of a larger national patient safety strategy. Hopefully, the framework proposed in this paper may serve as a template to allow other countries to develop effective governance structures and case selections strategies that are adapted to local needs.

\subsection{Research question}

In response to this gap in knowledge, the following research question was identified:

What is an effective framework to strategically select nationally reported serious adverse events in healthcare for investigation to improve patient safety?

To address this research question, this paper will perform a literature review to identify key themes, and subsequently interview key stakeholders from the Norwegian regulatory context as well as a UK based national investigative body. The findings will be used to develop a novel strategic framework for setting up a new investigative body.

See Table 1 for an overview of the key regulatory bodies in the Norwegian and UK based contexts.

Table 1. National health agencies and regulatory contexts

\begin{tabular}{|c|c|}
\hline $\begin{array}{c}\text { Regulatory } \\
\text { context } \\
\text { Norway }\end{array}$ & Department of Health and Social Care \\
& The Norwegian Health Directorate \\
& The Norwegian Health Inspectorate \\
\cline { 2 - 2 } & The Norwegian Healthcare Investigation Board \\
\hline $\begin{array}{c}\text { United } \\
\text { Kingdom }\end{array}$ & Health Safety Investigation Branch \\
& Quality Care Commission \\
\hline
\end{tabular}




\section{Literature review}

\subsection{Results from literature search}

\section{Academic literature and policy document review}

A review of relevant academic literature was performed using several combinations of keywords pertaining to key topic areas. Additionally, the most important health policy documents for relevant government health agencies were mapped by identifying relevant regulatory and policy. See Appendix 7.1 for details on search methodology and results.

\subsection{Summary of main arguments}

This review shows that while there is substantial literature on the various methodologies to investigate serious adverse events there is a gap in the literature when it comes to overarching frameworks that address issues such as the role of governance, monitoring trends and risks, building a strategic portfolio and criteria for individual case selection criteria. The literature review was therefore useful in identifying the key themes for further exploration in the subsequent semi-structured interviews. Ultimately, the themes also helped provide a foundation for the proposed novel theoretical framework (See Section 4. Figure 7).

Interestingly, these issues have been addressed more comprehensively for other safety critical industries such as the aviation and transport sectors. However, policy document reviews reveal that some of these issues have remained important concerns for policy makers.

\section{Role of governance}

Independence and importance of separation of powers

McCrae et al (2014) point out that the healthcare sector can draw on experiences from other industries such as aviation in setting up independent investigative bodies. The paper further argues for the importance of giving the agency comprehensive authority to collect data and address issues across all levels of governance. This is necessary to achieve system-wide learning which has not been possible in the current model where limited local investigations fail to address systemic factors. Furthermore, an exclusive focus on learning and improvement without assigning legal liability or use findings in attempted prosecution helps promote continuous improvement.

These findings were further expanded by Wiig et al (2018) who pointed to the importance of investigative bodies that are independent, systemwide, learning-focused and multidisciplinary. However, the same paper also discusses the importance of the need for a national collective effort of all stakeholders to help effectuate lasting change, improvement, and learning. 


\section{$\underline{\text { Stakeholder engagement }}$}

Interestingly, there was also a gap in the literature when it comes to comprehensive stakeholder engagement in the process of selecting cases. Indeed, if the investigative body looks at cases or issues which are viewed as irrelevant by the dominant players including clinicians, professional bodies, and other regulatory agencies its recommendation may gain limited buy-in.

Indeed, new investigative bodies such as the UK based Healthcare Safety Investigation Branch (2017) have published some views on the importance of this. Also, manuals in adverse event investigation in other sectors such as aviation has also pointed to the role of stakeholder engagement in case selection (Fultron Aviation Corporation: Improving Stakeholder Engagement, 2017).

\section{Health policy implications}

Indeed, these were important arguments made in favour of strong independence when the Norwegian Healthcare Investigation Board was being set up (Norwegian Government Policy Paper: NOU 2015: $11,2015)$ and led to a strong legal framework to ensure independence from the Health Department and other governance structures (Act of The Norwegian Healthcare Investigation Board, 2019).

Furthermore, the Norwegian Health Investigation Board was legislated a mandate focusing on learning and improvement without sanctioning authority, which are retained by The Health Inspectorate ("Act of Health Care Supervision," 2021). Thus, these laws provide a strong legal foundation for separation of investigative powers providing reassurance to potential informants. Indeed, there is further legal guarantees that the findings from investigations by the Health Investigation Board cannot be used in criminal proceedings or sanctions by employers. In contrast, the parallel agency in UK, The Health Safety Investigation Branch in UK has not been afforded similar protections ("New bill to improve patient safety," 2017) and face challenges in protecting informants from coroner's inquest and other challenges from law enforcement authorities.

\section{Strategic portfolio}

There were limited results in the literature on how to construct an appropriate portfolio of cases to maximize systems wide quality and safety improvement given resource constraints. This is further confirmation that the selected research question for this paper is indeed novel and has potential to add new knowledge. Wiig et al (2020) argued for a more comprehensive approach in healthcare accident investigations drawing on a wider field of organizational thinking, system dynamics and risk modelling to assess underlying systemic risks. This broader approach could be a helpful stepping-stone in setting up a useful theoretical framework for case selection. 


\section{Risk and trend monitoring}

McCrae (2015) points to several challenges pertaining to systematic reporting and monitoring of adverse incidents in healthcare. While other high-risk industries monitor reports to identify new and emerging risks, in healthcare reporting is more often inappropriately used to monitor performance. Furthermore, there is a tendency in healthcare to encourage reporting everything, while other industries may focus of areas that could provide serious or novel insights. Importantly, in other industries the incidents are coded pragmatically to allow for rapid analysis and overview, while in healthcare the incident coding systems often unsuccessfully try to capture complex realities. Woloshynowych et al (2005) also points to the relevance of taxonomies from incident monitoring systems in other industries. Furthermore, Hillestad et al (2005) discusses the potential of electronic health records could help monitor and improve patient safety potentially saving more than USD 80 billion in the US alone.

\section{Individual case selection criteria}

There is limited information available on which criteria should underpin the selection of adverse incidents for investigation. Importantly, the UK based Healthcare Safety Investigation Branch (2021) have published their overarching criteria to identify relevant cases for national investigations. First, they consider the outcome impact which looks at the totality of harm caused by the incident for all involved parties: patients, families, and staff. Second, they consider systemic risk which describes how widely the issue affects the healthcare system. This includes an assessment of the longevity of the issue and the risk of escalation. Finally, learning potential, focusing on producing new insights about patient safety that can inform recommendations for improvement. Others, such as Edmondson et al (2004) point to the rarity of organizations that can systematically engage in learning from adverse incidents. Indeed, several powerful systemic barriers are identified including leadership and creating the psychological safety to allow learning within organizations. 


\section{Methodology and Data}

\subsection{Overview}

The aim of this paper is to develop a novel theoretical framework to assist policy makers set up a new national healthcare safety body and a strategic case selection mechanism.

The following steps were taken to achieve this:

1. Academic literature and policy paper review (See Section 2)

2. Selection of themes for semi-structured interview and analysis

3. Performing semi-structured interviews with selected key stakeholders

4. Developing a novel theoretical framework with these components:

- A conceptual framework for selecting adverse cases for investigation

- Key strategic questions for policy makers

\subsection{Selecting themes for analysis}

\section{Selecting themes for interviews \& analysis}

Drawing on insights from the identified gaps in the literature four key themes were identified on that could serve as a foundation for the interviews, analysis and developed framework:

(1) Governance and independence

(2) Building a strategic portfolio

(3) Monitoring risks and trends

(4) Selection criteria for individual cases

\section{The Risk Management Framework}

To further test the viability of these themes, their viability was assessed in the recognized US government Risk Management Framework ("Risk management framework," 2020).

This is a policy standard that was originally developed to ensure information's security and risk management within a development cycle. However, the model has seen wider applications and has been adapted to several different settings. Indeed, currently it is viewed as a standard that applies to widely systems engineering and has also been adapted to healthcare settings.

See Figure 1 for overview. 
Figure 1. Risk management framework (RMF)

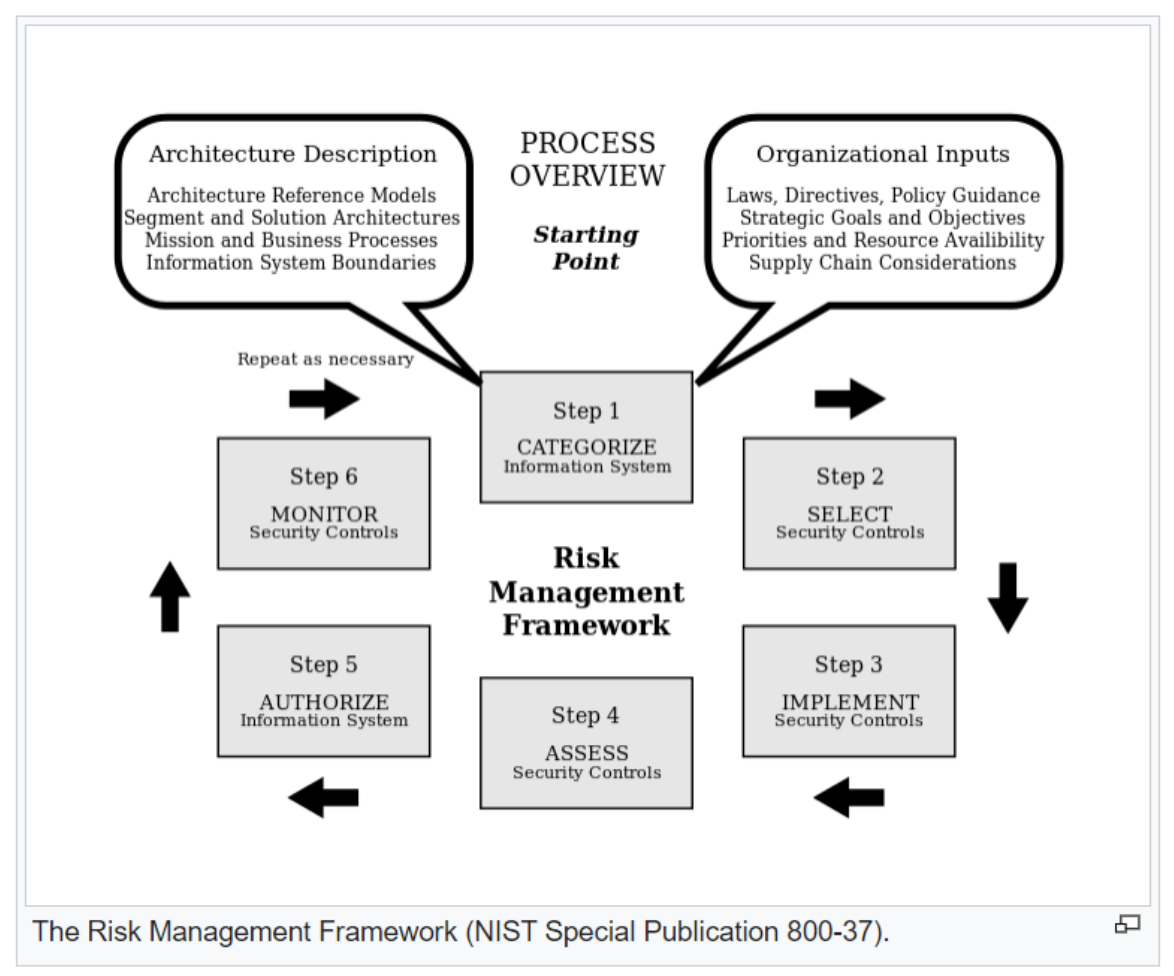

Source: Creative commons license (CC BY-SA 3.0). By Zagaberoo (18 December 2011).

Briefly, the Risk Management Framework starts by categorizing the type of system including governance, strategy, and structural issues. Next, the system requires selecting a baseline of criteria for acceptable operations. This is followed by implementation and assessment of systems performance by a third party. In turn, this ensures that only safe processes can proceed, which are then continuously monitored for emerging risks. Adapting this model to the challenge of identifying adverse cases for investigation we find this could be mapped to the following steps:

- Identification: Where to identify risk and adverse events?

- Analysis: Quantify impact and probability for each type of adverse events

- Evaluation: Classify events to prioritize resources to high-risk regions/diseases etc.

- Responses: Develop prevention/mitigation strategies to reduce adverse events.

- Assessing outcomes: Evaluate outcome of new policies and mitigation strategies.

\section{Relevance of selected themes}

As can be seen from this model, categorizing governance structures remain an important step, but there are no explicit recommendations on how these structures should be set up. Monitoring of outcomes is also identified as a crucial step, but the model does not describe approaches to detecting emerging risks. The framework provides suggestions on how to prioritize resources to high-risk areas, but there are no 
clear indications on how to build a portfolio when strategic selection is necessary due to resource limitations. The Risk Management Framework appears to both confirm the relevance of our selected themes for further investigations as well as point to gaps in current knowledge.

\subsection{Interviewing key stakeholders}

\section{Rationale for selecting organizations}

For this study senior policymakers at key national health regulatory agencies and organizations in Norway and the UK were selected for semi-structured interviews. As can be seen in Figure 2 below, these organizations operate in a complex interconnected strategic regulatory landscape. By interviewing individuals from these organization this paper achieves a broad coverage of the opinions key policymakers in the Norwegian and UK health sectors, see Table 2.

Figure 2. Roles of key national health authorities

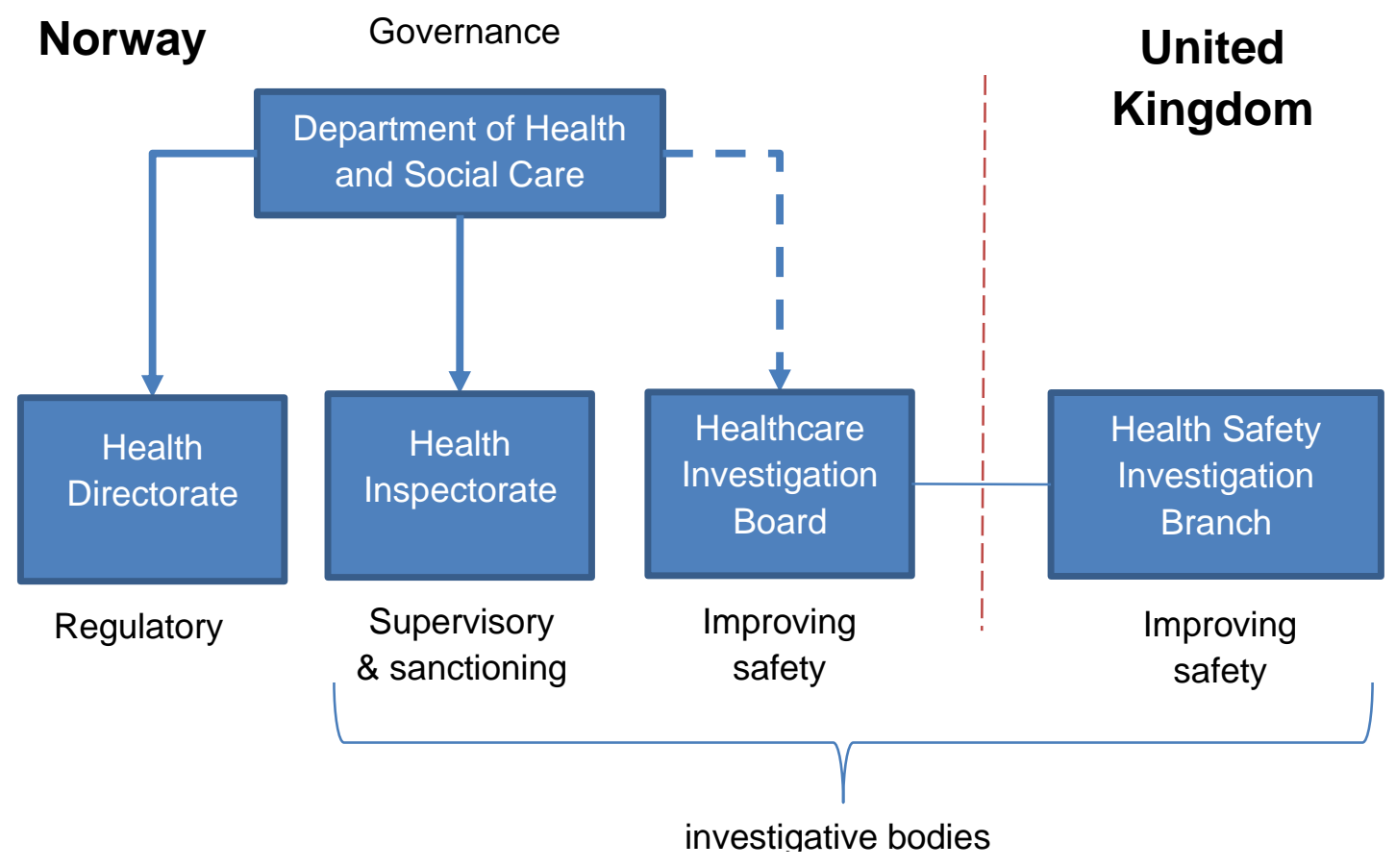

Legend: The Department of Health and Social Care in Norway is the central regulatory agency and has administrative and instructive authority over underlying government agencies. An important exception is the Healthcare Investigation Board which cannot be instructed in its choices of cases or methodology (this is signified by the dotted blue arrow). The UK based Health Safety Investigation Branch in the UK has a similar mandate but enjoys less legal independence. 
Table 2. Informants and their roles

\begin{tabular}{|cll|}
\hline Informant \# & \multicolumn{1}{c|}{ Role of informant } & \multicolumn{1}{c|}{ Agency } \\
\hline 1 & Director General & Department of Health and Social Care (Norway) \\
\hline 2 & Senior Advisor & Health Directorate (Norway) \\
\hline 3 & Director General & Health Inspectorate (Norway) \\
\hline 4 & Deputy Director General & Health Inspectorate (Norway) \\
\hline 5 & Direct access/data source & Norwegian Healthcare Investigation Board (Norway) \\
\hline 6 & Medical Director & Health Safety Investigation Branch (United Kingdom) \\
\hline
\end{tabular}

$\underline{\text { Roles of the health regulatory agencies }}$

- The Department of Health and Social Care is the central governance authority that enacts current government healthcare policies. Furthermore, it has an administrative authority for several underlying government healthcare regulatory or investigative agencies.

- The Health Directorate has a coordinating and regulatory function. It advises the Health Department and issues regulations on its behalf. The directorate also has a role in monitoring patient safety and facilitating learning across the system.

- The Healthcare Supervision Board (Inspectorate) investigates serious adverse events and has a statutory and sanctioning and authority. In cases of regulatory breach or malpractice and the agency can issue fines or penalize health professionals by retracting their license to practice.

- The Healthcare Investigation Board (NHIB) is an independent government investigative agency. It investigates serious adverse events with the aim to address systemic risk factors and improve patient safety. However, the agency but does not sanction or take punitive actions.

- $\quad$ The UK based Health Safety Investigation Branch (HSIB) has a similar mandate as the NHIB. It too has the mandate to improve patient's safety without apportioning blame or liability. However, it does not have legal independence and informants could be compromised.

\section{The format of the interview}

The interview followed a semi-structured template that was developed based on identified strategic themes. The interviews were performed using online tools such as Skype or Teams and were limited to 
60 minutes. An interview-template (see Table 3 below) was developed allowing the interview to cover the four main themes with corresponding sub-themes.

As the interviewees were senior health policy officials a simplistic structured interview would have been inappropriate. The interviews therefore followed a looser semi-structured approach where the topics were "explored" in a more conversational setting. This approach provided more flexibility during the interview, making it easier to pursue naturally occurring threads or topics in more depth.

Although these were senior informants, their identities were intentionally semi-anonymized in this report and only referred to as informants 1-6. Furthermore, the following discussion and analysis avoids referring to individual statements, but rather collates and summarizes areas of agreement and disagreement among the informants. This approach allowed the informants to engage in the discussions more freely, without concerns of being directly quoted.

Table 3. Semi-structured interview template with themes and sub-themes

\begin{tabular}{|c|c|}
\hline Interview themes & Sub-themes \\
\hline Governance & $\begin{array}{l}\text { Independence } \\
\text { - Independence of investigative } \\
\text { - } \text { Routhorities and separation of powers } \\
\text { Stakeholder engagement } \\
\text { - Role of regulators } \\
\text { - Professional bodies } \\
\text { - Patients and families }\end{array}$ \\
\hline Risk monitoring & $\begin{array}{l}\text { - } \quad \text { Trends versus risk } \\
\text { - } \quad \text { National versus local } \\
\text { - } \quad \text { Areas with underreporting } \\
\text { - } \quad \text { Unexplained variation } \\
\text { - } \quad \text { Crises response } \\
\text { Alternative sources (media, quality } \\
\text { indicators, operational data, } \\
\text { registries) }\end{array}$ \\
\hline Strategic portfolio & $\begin{array}{l}\text { - } \quad \text { Strategic coverage of health sector } \\
\text { - } \quad \text { Broad coverage of risk landscape } \\
\text { - Obligatory inclusion of certain groups }\end{array}$ \\
\hline Selection criteria & $\begin{array}{l}\text { - Seriousness of outcome and } \\
\text { importance of near-misses } \\
\text { - Systemic risk (outcome and } \\
\text { frequency) } \\
\text { - Learning potential }\end{array}$ \\
\hline
\end{tabular}




\section{Result and Discussion}

\subsection{Key findings}

This study builds collects data from several sources: First, a review of the existing literature on relevant themes in the health sector and other high-risk industries. Secondly, a review of key health policy documents issued by the key national health authorities (See Section 2 for an overview). Thirdly, the views of senior officials from key stakeholder organizations on the identified themes: (1) governance and independence, (2) monitoring risks and trends, (3) building a strategic portfolio, and (4) individual case selection criteria (“Individual Project CJBS: Informants 1-6," 2021).

The main findings from the interviews are presented as key insights in the section below. In general, the viewpoints of the informants are presented in a collated form where there was substantial agreement or disagreement. Individual informants are only referred to in cases where they are alone in having argued for a specific point.

\subsection{Findings, Analysis and Discussion}

\section{Governance and independence}

One of the important questions that was explored with the informants was the need for an independent national health safety investigative body with a focus on systems learning. Independence ensures that case selection is not influenced by the current political trends or other external factors. Furthermore, this allows the agency to base its decisions on method of investigation on actual system needs. Indeed, the need for an independent investigative authority with a focus on learning was strongly supported across all the informants. There was also strong support for the idea of investigative learning authority without any powers to sanction or initiate punitive actions against individuals or organizations.

Informant 3 pointed out that politician will retain the ability to influence government agencies through various means (exerting pressure through media, changing the mandate, budgetary cuts). Nevertheless, there was support for the idea that a strong legal mandate establishes mechanisms that helps safeguard independence. Furthermore, Informant 2 suggested that a health investigative agency could be placed under a different department than the Health and social care department to mitigate undue political influence. Robust internal mechanisms to deal with political pressure should also be put in place, including legal competence to effectively challenge requests by politicians and media savvy to resist sustained campaigns by narrow interest groups.

Indeed, the need for independent investigators has been recognized internationally as well. In the UK this has led to the creation of Healthcare Safety Investigation Branch. However, informant 6 pointed to challenges due to current limited legal protections which has led to informants fearing consequences of 
coroner's inquests. While the organization has resisted efforts to hand over data, this has not yet been tested in court. Furthermore, the UK Department for Health and Social Care retains the power to hire and fire staff, which severely restrains the independence. However, there is currently efforts under way get a stronger legal framework passed in the UK. (Macrae and Vincent, 2014; Wiig and Macrae, 2018)

Additionally, it is worthwhile to consider the experiences of the Norwegian Healthcare Investigation Board which has strong legal independence from the Norwegian health department. This author has direct access to information about this agency (Informant 5, 2021). Although the organization has only a couple of years of experience, the strong legal independence has afforded it the chance to address systems level risk factors while building trust with regulators, professional bodies, health personnel and patients. The systems levels risks include issues that touch on health economics as well as existing legal frameworks and regulations. This provides a platform for recommendation that target even the Health Department and Social Care department as well as lawmakers.

However, the extensive independence and investigative powers also carries inherent risks as the agency should become too self-sufficient. Indeed, the Norwegian Healthcare Investigation Board has sought to mitigate this by appointing an advisory panel with broad representation from across the healthcare system with experts and national voices in areas as diverse as the specialist and primary healthcare services, health economics, technology, personal data protection, data mining, quality improvement. While the advisory panel does not have powers to instruct the board, its suggestions are taken very seriously, and their combined recommendations are rarely rejected outright. The board has intentionally avoided creating a panel that represents various stakeholder or interest groups as this would never become wholly representative and could end in more partisan lines of discussion and argument.

\section{$\underline{\text { Key insights }}$}

- A centralized investigative learning authority is key to ensuring coherent systems learning across the healthcare system on a national level. A clarification of roles and separation of powers is necessary where there are multiple investigative authorities.

- Independence of investigative learning authorities is necessary to ensure freedom in selection of cases from political pressures. The independence and should be secured across several dimensions: legally, administratively, and organizationally.

- Independence together with separation of powers (i.e. the investigative agency should only have a focus on learning) provides protection to informants from sanctions and legal liability.

- The investigative authority should also be provided with the mandate to investigate other authorities including the Health Department and other government agencies. 
- Independence should be coupled with a consultative approach where stakeholders are constructively engaged to mitigate biases when selecting cases.

- The investigative authority should work closely with health personnel, patients, and their families during all steps to ensure rebuilding of trust where there has been a breach.

\section{Stakeholder engagement}

Ultimately, the investigations serve as part of a larger patient safety effort. It is important to note that the selection mechanisms should be adapted to local needs. Indeed, there was consensus among the informants that a broad approach towards stakeholder engagement is needed to ensure that the findings are recognized as relevant and implemented efficiently in the various healthcare jurisdictions. This also ensures that the validity of the findings and recommendations are not systematically challenged after investigation have been completed. Several of the informants also pointed to the importance of making sure that stakeholder engagement does not compromise independence.

$\underline{\text { Key insights }}$

- Investigations of adverse events should be viewed as part of larger national patient safety effort. Broad stakeholder engagement is important but should not compromise independence.

- Regular discussions with stakeholders (regulators, experts, professional bodies, clinicians and patients or families should be involved to help selecting strategic areas.

\section{Monitoring trends and risk}

There were differing views among the informants on the value of monitoring for trends of reports of adverse events. Some informants believed that the most significant areas of risk on a national level have already largely been identified, and primarily considered monitoring it locally useful (e.g., monitoring a specific jurisdiction or hospital). However, other informants contested this viewpoint and pointed to concrete examples where monitoring for trends in adverse events have yielded new insights. A concrete example where trend monitoring has yielded new knowledge was provided by Informant 3: there was previously a wide-spread belief that the most important complications during blood transfusions were the use of wrong blood type or spread of infections. However, data monitoring has demonstrated that transfusion-related lung complications are a much more common occurrence. These insights have led to changes in practices (Toy and Lowell, 2007). 
It is also worth noting, as some informants pointed out, that reports of adverse events do not accurate reflect the incidence of adverse incidents and could be skewed for due to a variety of reasons: there could be systematic underreporting due to a culture of fear or lack of understanding of purpose of reporting. Similarly, overreporting could be a result of local power struggles.

In contrast to monitoring for trends in in reports, there was broad consensus among the informants that variation in quality indicators across providers could point to important underlying risk factors. Health registries remain underutilized and could provide a rich resource for big data analysis. Indeed, as more high-quality data is accessible in health registry and data sharing becomes more common could allow for more robust sharing of data. However, this requires compliance with personal data privacy laws such as General Data Protection Regulation (“General Data Protection Regulation,” 2021).

Informant 6 pointed to the NHS where there is a centralized emerging risks team that analysis diverse data sources and provides data to different government agencies. There are similar moves in Norway to set up a centralized data analysis unit to analyse data in health registries and serve other agencies. Additionally, the media may represent an alternative source that could detect areas of risk that are underreported due to their independent sources and methodologies of investigation. There is therefore a case to be made to monitor the media as a supplemental source for identifying cases and areas of risk.

Finally, there is also the issue of the value of monitoring during times of rapidly developing crisis, such as the pandemic. One could for example detect changes in a variety of data sources including reporting, complication rates, activity levels and quality indicators. These all represent distinct areas of risks and could be helpful in assessing the long-term patient safety consequences of the pandemic. Indeed, there could be reports of frequency clusters as well as changes in quality indicators over time that help identify areas of increased risk. The Norwegian Healthcare Safety Investigation Board has recently published trends in Mental health of children and adolescents (2021) which was well received in the national interest groups and patient safety organizations.

See also Figure 3 below. 
Figure 3. Monitoring risk trends

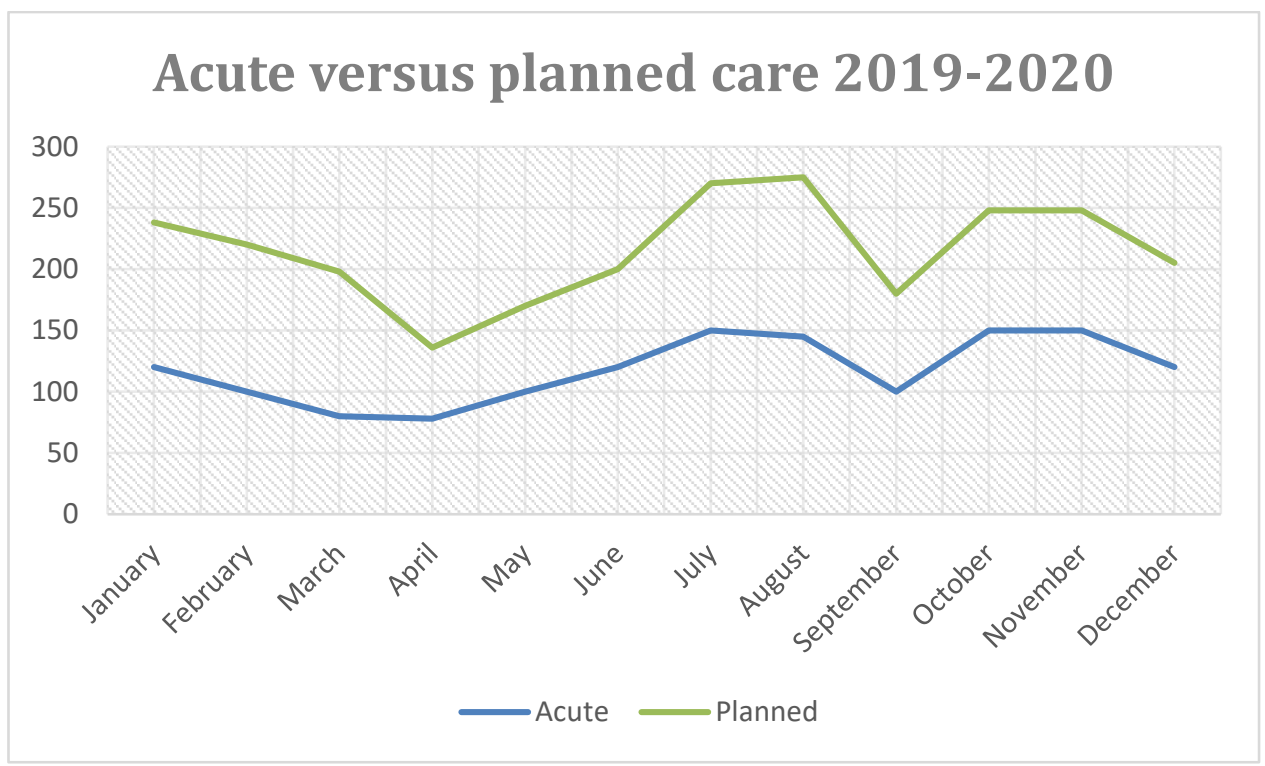

Source: Adapted from ("The Norwegian Healthcare Investigation Board: Mental health of children and adolescents one year into the pandemic," 2021)

$\underline{\text { Key insights }}$

- There is controversy regarding the importance of monitoring trends in adverse event. While some informants argue that main areas of risk on a national level have already been identified, others provide concrete examples where monitoring have yielded new insights.

- Trends, clusters or emerging variation in national long-established quality indicators may suggest increased risks and warrants further investigation. Health registries remain underutilized and could serve as a source for big data analysis.

- A centralized and independent analysis unit with the capability to analyse data from several sources could allow for more comprehensive and rapid identification of emerging risks.

- Monitoring operational data during extensive systemic disruption (such as during the COVID pandemic) could be help identify emerging risks.

- Alternative data sources such as the media, conference presentations, operational data and other unpublished sources may serve as indicators of areas suffering from underreporting. 


\section{Building a strategic portfolio}

There was disagreement among the informants of the importance of building a strategic portfolio. Some argued that one should always target the areas of highest risk for investigation even if they are all concentrated within in a limited sector of the healthcare system. Other informants argued for the importance of inclusion of particularly vulnerable or excluded groups such as the elderly, those with psychiatric or drug abuse issues, children, and refuges. Indeed, these groups have increased risk for adverse outcomes also outside of the healthcare system and could be targeted also from an equity standpoint.

Several informants were of the view that there is a case to be made for a broad coverage of sectors from an equity point of view. Additionally, in this author's view, a broader range of cases across different sectors could help to uncover a wider range of systemic factors. For example, investigating two similar cases in somatic care could provide access to a more limited range of underlying systemic factors. In contrast, investigating one somatic case and one case in radiology could access a broader range of systemic factors while providing insights into factors which act across sectors. See Figure 4 below.

There were different approaches to building a strategic portfolio among the informants. Informant 6 advocated a strategic bucketing approach, that is to designate a certain proportion of cases annually to target some pre-selected strategic areas. For example, the organization could choose delays in cancer treatment together with a couple of other areas to strategically target a specific year. The remaining cases in the portfolio could be selected on a rolling basis. An alternative approach is to build a pipeline of cases that broadly cover the strategic areas and continuously evaluate the strategic fit of newly selected cases within the portfolio.

There was consensus among the informants that a strategic portfolio should take into consideration the fact that there is considerable underreporting of adverse events throughout the entire healthcare system. This could be a result of a culture of fear or limited understanding of the potential learning benefits of systematic reporting. However, there was not a clear consensus among the informants on how to counteract this issue. Some approaches have already been described in the section on monitoring trends and risk. Another method supported by some of the informants would be to intentionally include some randomly selected cases (that pass a minimum threshold of seriousness of outcome) in the overall portfolio of adverse events for investigation. 
Figure 4. Synergies of broad and diverse case selection

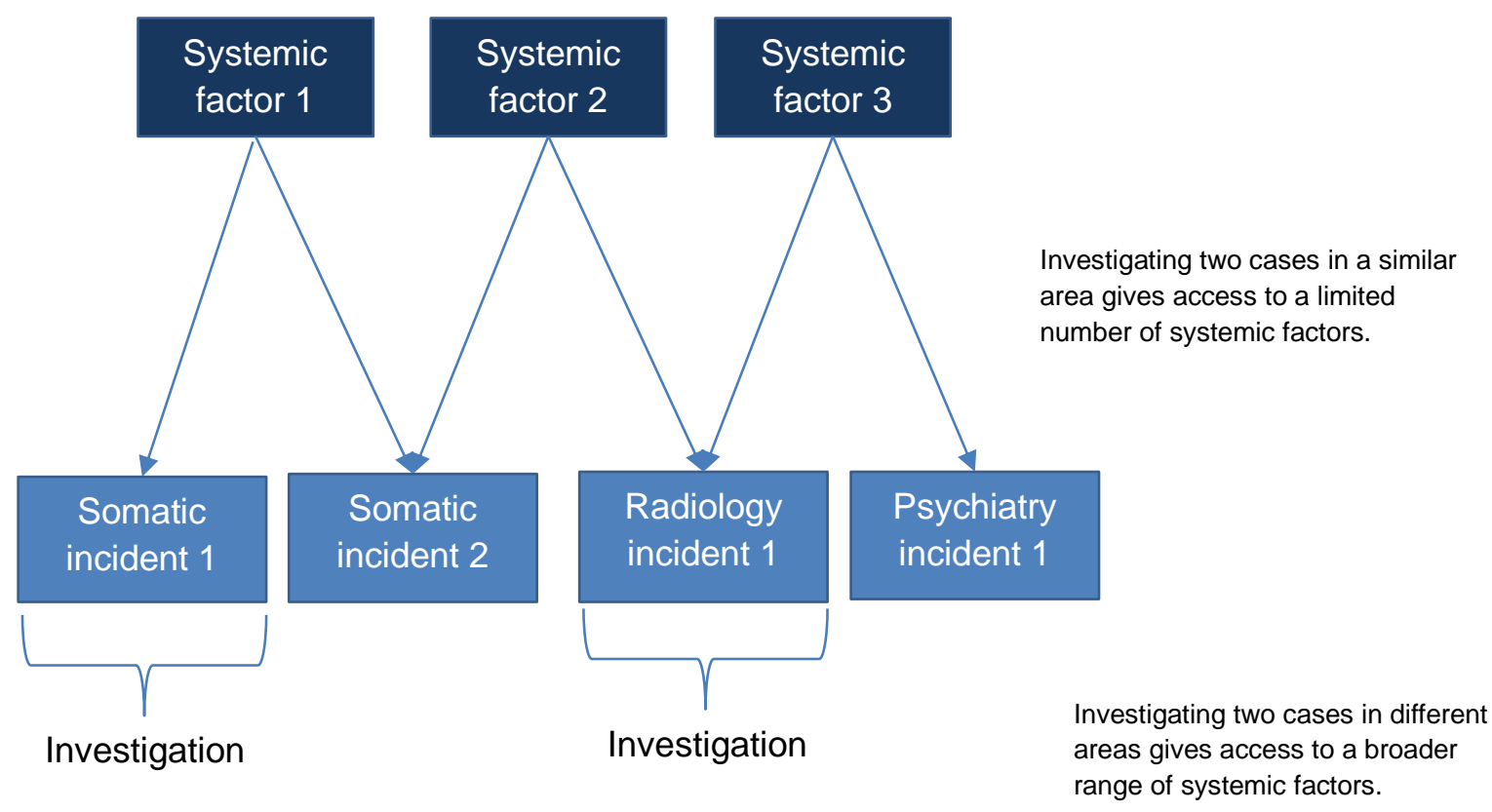

Source: New figure developed and drawn by this author (2021)

$\underline{\text { Key insights }}$

- There are conflicting opinions on the appropriateness of a portfolio approach: Some argue that cases should be selected based on systemic risk and learning potential even if that means that all cases are from a specific part of the healthcare system. Others argue that a broad coverage of the healthcare system (e.g., somatic vs psychiatry or primary vs secondary services) should also be an important consideration.

- One model of building a strategic portfolio allocates a certain proportion of cases based on annual strategic choices, while the remaining cases are selected on a rolling basis (this approach could be called "strategic bucketing").

- Several informants argued for the importance of prioritizing cases involving vulnerable and/or excluded groups such as children, elderly, psychiatric patients, drug addicts and refugees. 


\section{Individual case selection criteria}

General considerations

Several informants pointed to the inherent opportunity cost in selecting a case for investigation as resources are diverted away from other potential investigations. Therefore, a decision to start an investigation should incorporate some form of cost-benefit analysis balancing the opportunity cost against potential benefits in reducing systemic risks. Indeed, there are competing considerations: e.g., reduce immediate risk or target areas ripe for long-term risk improvement. Indeed, a tool that could be employed as pointed by some informants, is a traditional Risk-Value-Cost-Effort Matrix. See Figure 5.

Figure 5. Risk-Value-Cost-Effort Matrix

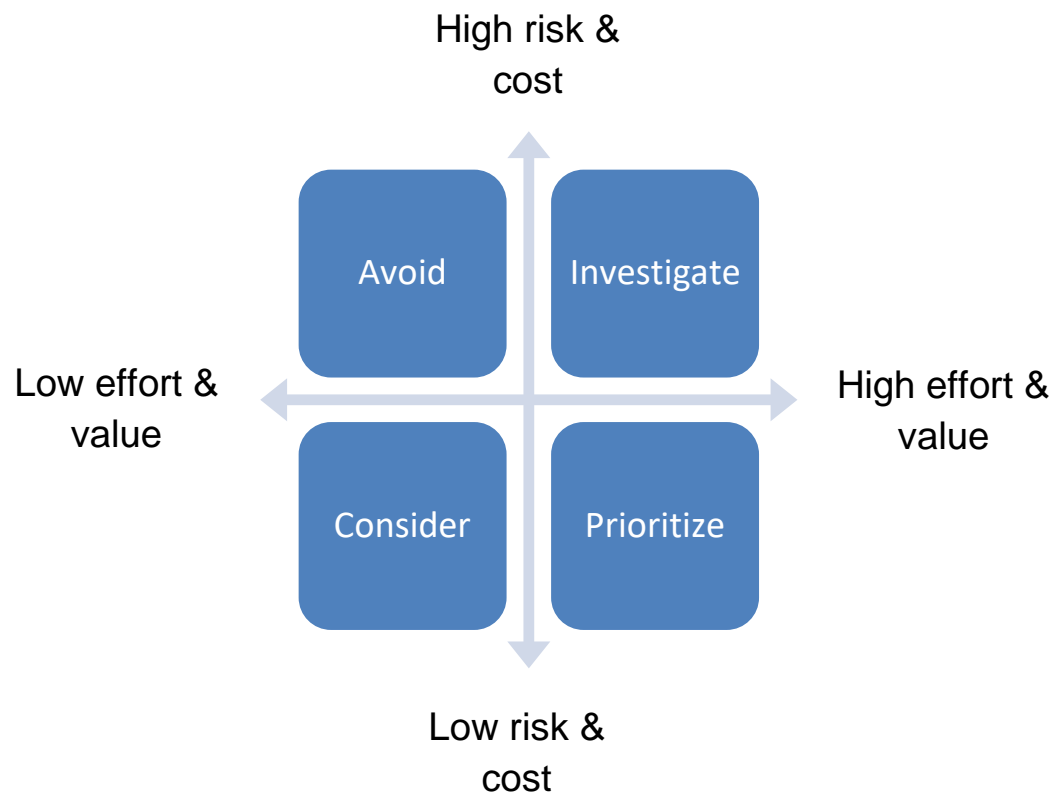

Source: Redrawn image from (Moran, 2018)

Another issue that was raised by the informants was the importance of restoring trust in the system. An independent and transparent case selection process could help establish trust with key stakeholders such as clinicians, patients, and their families.

\section{$\underline{\text { Seriousness of outcome }}$}

All informants recognized seriousness of outcome as an important criterion for selecting cases. First, it ensures that the selected cases most likely involve systemic reasons that could potentially lead to fatal consequence. Secondly, cases with serious outcomes have an emotional impact that increases the likelihood of learning after the incident. However, many also pointed to potential pitfalls with a onesided focus on seriousness of outcome as this could lead to a biased view of risk in the system. Several 
informants pointed to the importance of near misses or low-harm events as an equally powerful source for learning and improvement. Indeed, not all risks manifest themselves as serious outcomes and near misses could provide more complete pictures of the scale of the specific type of incidents.

\section{Systemic risk}

There was broad consensus among the informants on the importance of systemic risk as an important selection criterion. However, there are varying approaches to how this term should be operationalized. While most informants agree that systemic risk could be partially represented as a function of seriousness of outcome and frequency of occurrence, there was also a sentiment that this approach does not fully capture the idea of systemic risk. Several modifying factors were suggested including social responsibility and prioritizing cases involving vulnerable groups. The involvement of multiple actors across several parts of areas of the healthcare system were also suggested as indicators of systemic risk. Indeed, systemic risk could be viewed as the total burden the type of adverse incidents impose on the healthcare system. However, several informants made the point that the primary purpose should be to reduce the disease burden and that cost-savings should only be a secondary aim.

\section{Learning potential}

These was broad consensus among the informants that learning potential should represent an important pillar in case selection. Informant 1 made that point that a case could have high learning potential if it addresses an area where there is existing medical on procedure knowledge which has remained underimplemented. In contrast, another type of high learning potential case could address areas where novel medical, procedure of safety knowledge could be uncovered. For both types of cases, receptiveness of clinicians and providers to change practices in this area, could be considered as a factor in determining overall learning potential.

When assessing learning potential, experiences from the Norwegian Healthcare Investigation Board (Informant 5, 2021) suggest that most adverse incidents are connected to system level factors. For example, an adverse incident where a nurse administered too much insulin could be considered a simple case of technical barriers, or could be abstracted to system level factors such as resources, staffing, nurse training educations. A comparison of learning potential of individual cases should therefore always be performed on a similar level of abstraction.

See Figure 6 below. 
Figure 6. Systemic factors and targeting recommendations

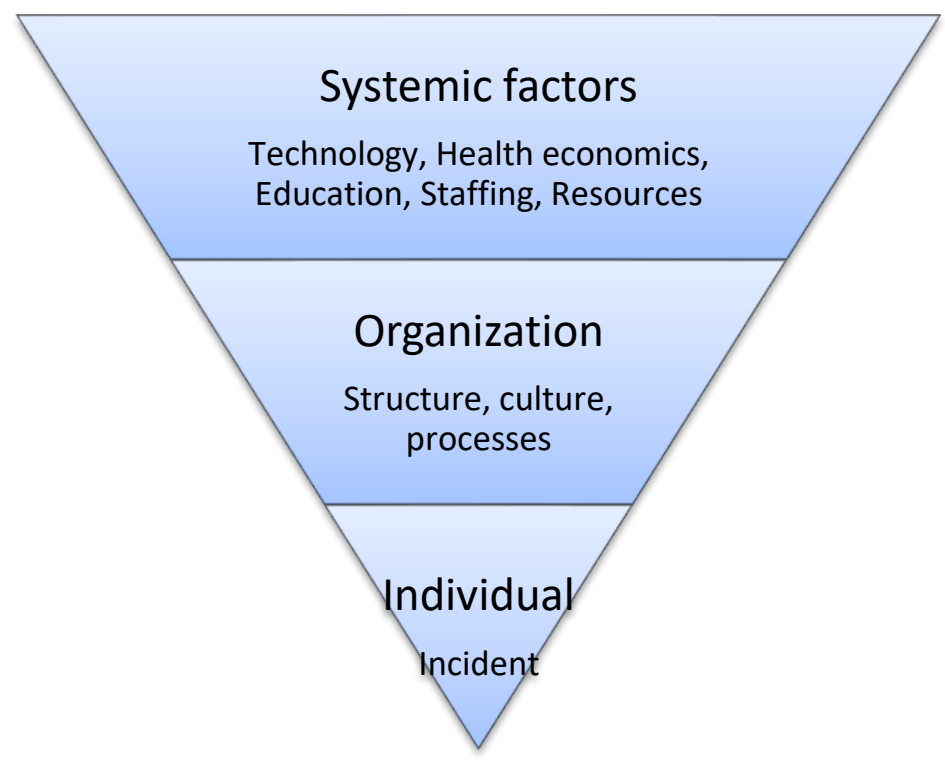

Source: Adapted from (“The Norwegian Healthcare Investigation Board. Strategy 2.0," 2020)

Key insights

- The decision to start an investigation should incorporate a cost-benefit analysis that balances the opportunity cost of starting an investigation and potential benefits in reducing medical risk.

- The case selection processes should be as transparent as possible and should be published to build trust with stakeholders, in particular health personnel and patients.

- Seriousness of outcome is an important selection criterion and could ensure that the investigation and recommendations will have a greater impact. However, near-misses and lowharm events may have as much learning potential.

- Systemic risk remains an important selection criterion and may be viewed as a function of seriousness of outcome and the frequency with which the type of event occurs. Other factors that could be considered are involvement of multiple actors and social impact.

- Learning potential remains an important selection criterion and may represent areas where existing knowledge is under-implemented or areas with potential for new knowledge. Areas which have remained blind spots for the system should also be prioritized. 


\subsection{Policy and managerial implications}

\section{A new framework for case selection}

The overarching goal of this paper is to develop a framework to aid in setting up national healthcare safety investigation bodies and a case selection that can be adapted to different local conditions. Indeed, different countries could present varying healthcare systems, regulatory contexts, and risks landscape.

As discussed earlier, based on a review of the literature and existing theoretical frameworks, four strategic themes were identified that were explored in semi-structured interviews with key stakeholders:

1) Governance and independence

2) Risk and trend monitoring

3) Building a strategic portfolio

4) Individual case selection criteria

On a conceptual level the novel theoretical framework can therefore be conceptualized as a cascade where more strategic themes naturally lead into more operational themes (Wright, 2021). In line with this thinking, Theme 1 or Governance can be viewed as the most strategic questions, including questions regarding the independence of the new national investigative body. Next, this raises questions from Theme 2 on how to effectively Monitor for trends and emerging risks. This in turn, flow readily into Theme 3 or the issue of building a Strategic Portfolio of cases. Finally, this culminates in Theme 4 which is the operationalized Selection Criteria for individual cases.

An alternative conceptualization, is a cyclical model which views the process as a dynamic process with some similarities to the Risk Management Framework Cycles ("Risk management framework," 2020). Indeed, here the cycle would also start at Governance and flow through the different themes, but in the end identified systemic risks could help guide the development of new Governance mechanisms thereby completing the circle.

See Figure 7 A-B for overview of the new model (cascading and cyclic).

Next, for each of the four strategic themes, several key questions were identified that policy makers should address when setting up a new national investigative body.

See Table 4 A-D below. 
Figure 7. A novel strategic framework for case selection (cascading and cyclic)

A. Cascading model

A strategic framework for case selection

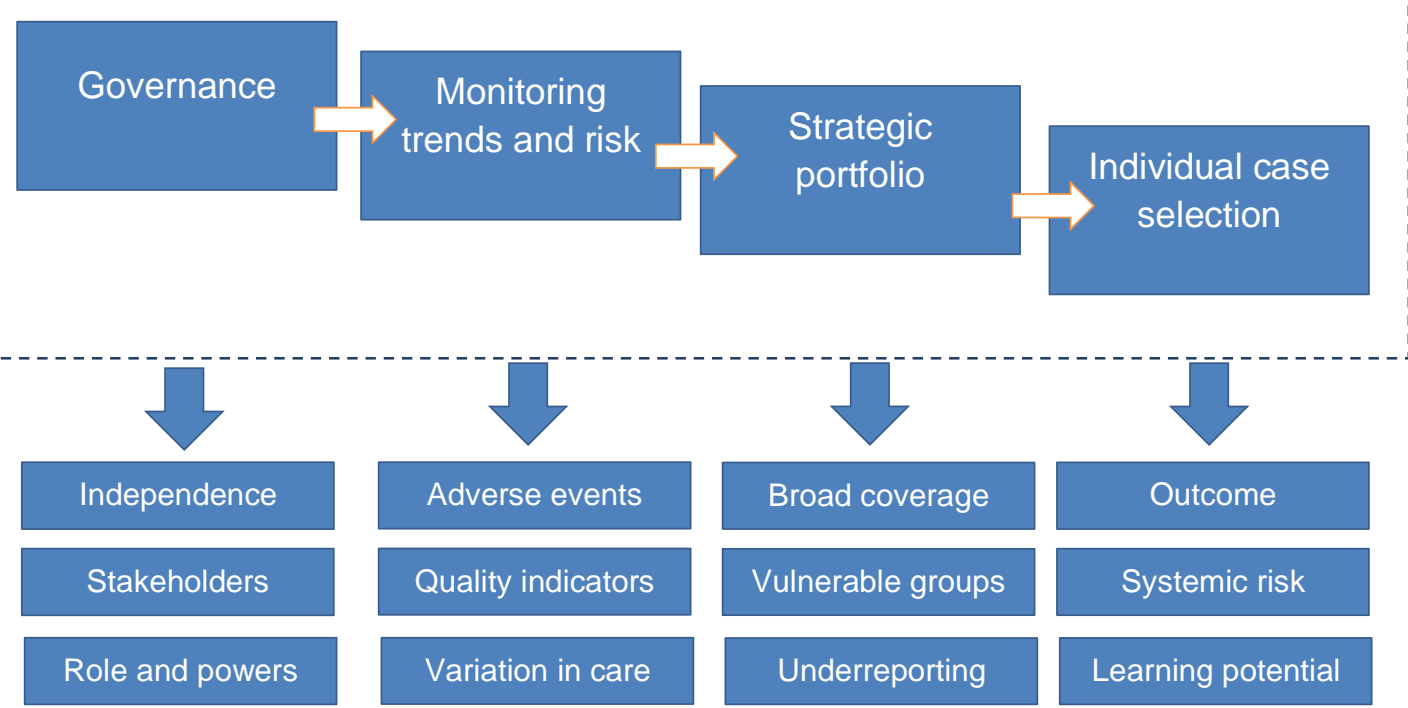

B. Cyclic model

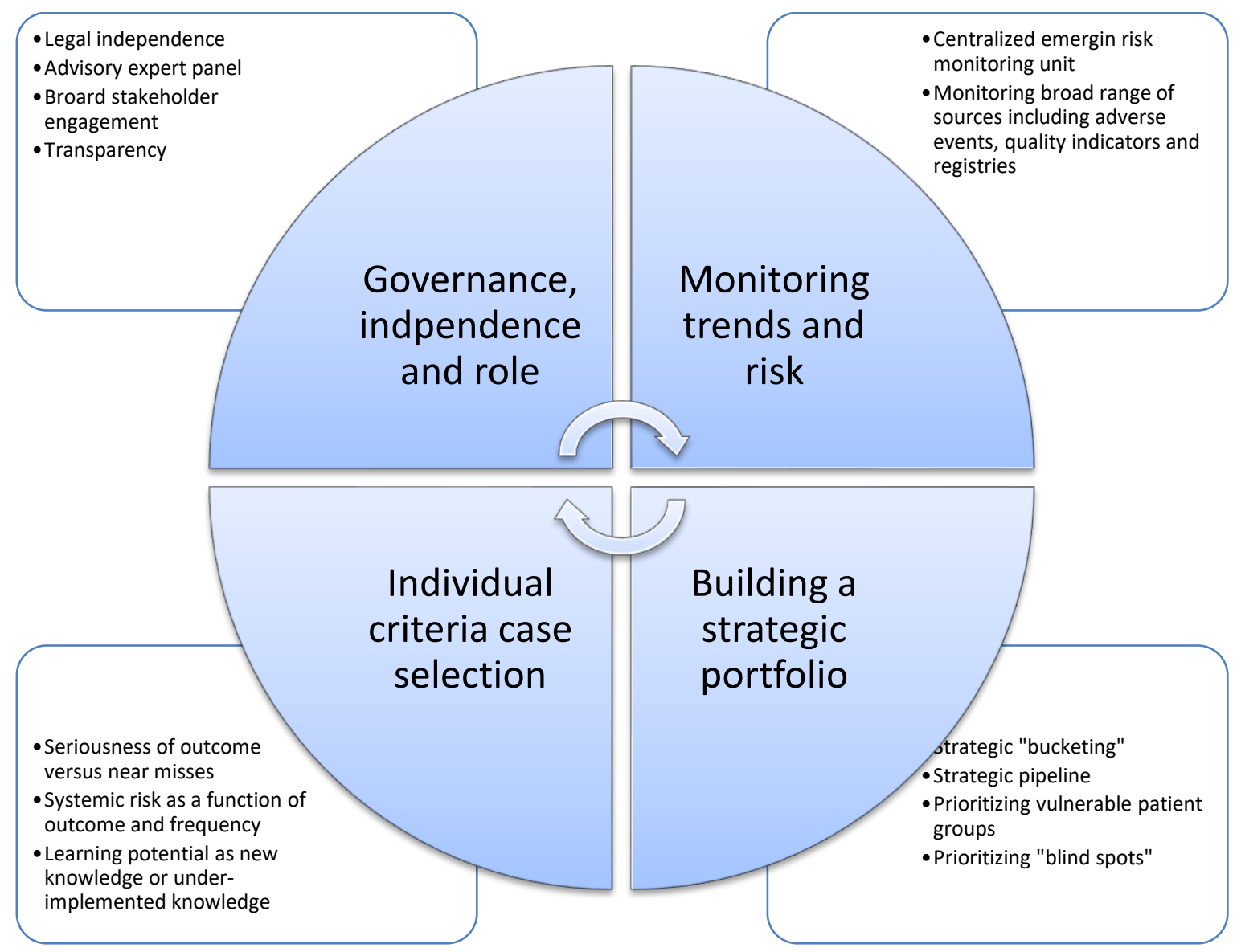




\section{Strategic questions}

As can be seen in Figure 7, for each of the identified themes there are several strategic areas that policymakers should address. These areas could be probed by asking questions that allow decision makers to consider important strategic issues when implementing a new government safety investigative body and a case selection mechanism. This paper recommends that these questions are addressed in a continuous manner as conditions may change after the agency has been set up and the mechanism has been in place for a while. Indeed, this will provide a cycle that can facilitate any necessary adjustments in governance structures or policies.

See Table 4. A-D below.

Table 4. A-D. Strategic questions to ask when setting up a new investigative body

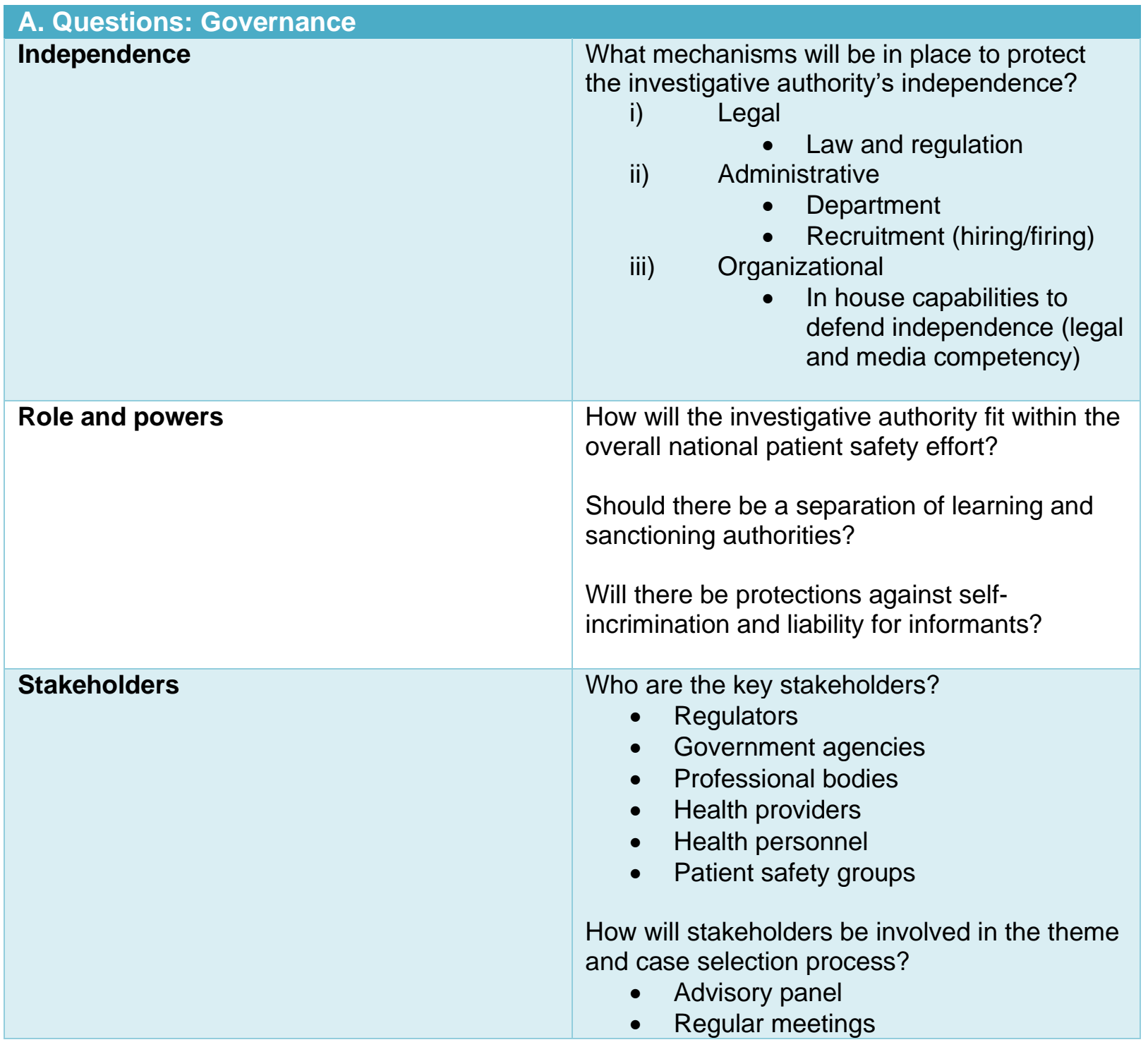




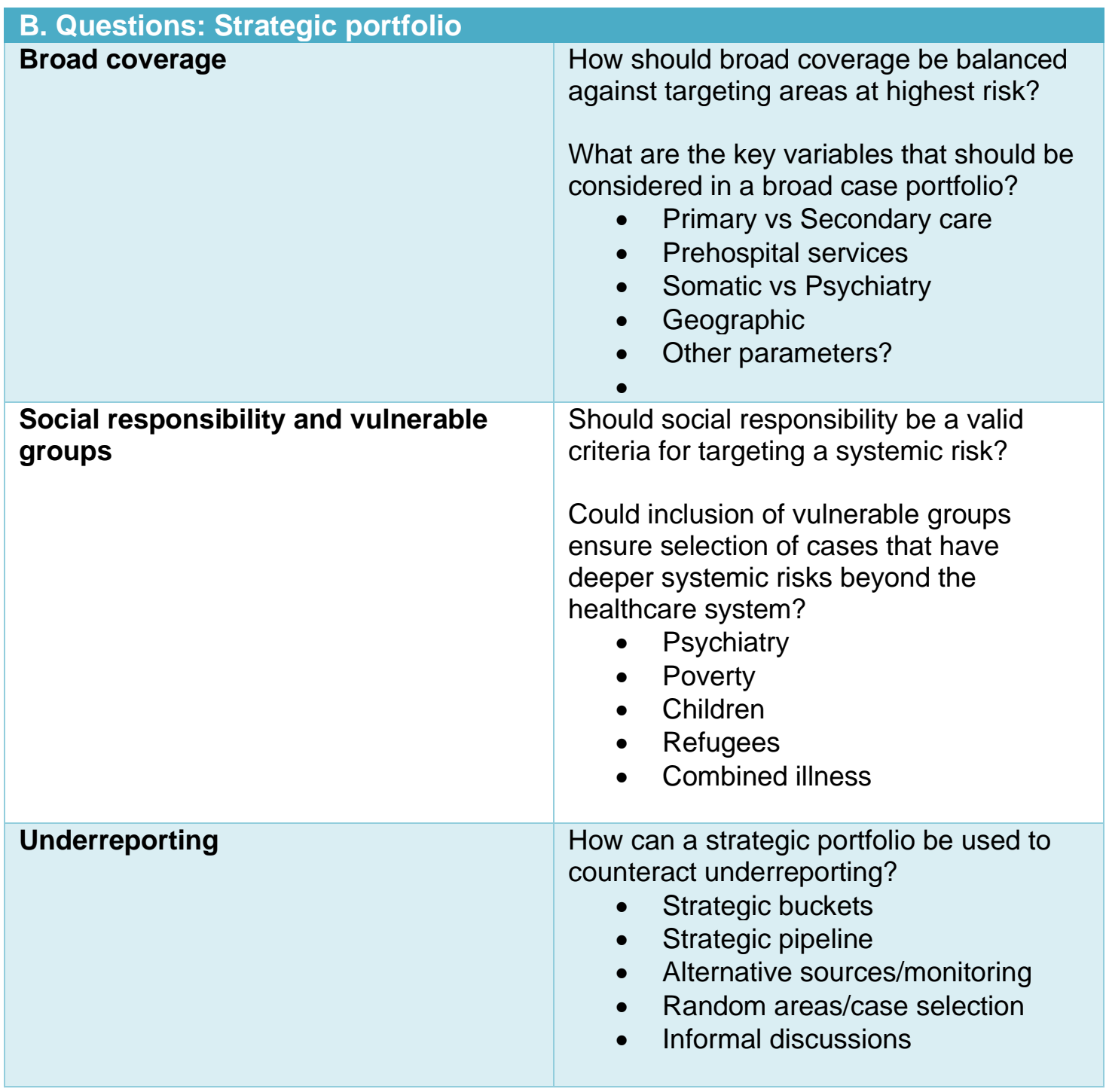

C. Questions: Risk and trend monitoring

Trends in adverse events

Should there be a centralized emerging risks and trends analysis unit?

How can adverse event reporting be standardized to ensure higher quality data?

How should underreporting be counteracted?

Trends in quality indicators

Unexplained variations (events, indicators, operational data, outcomes, and registries)
Should national quality indicators be used as a strategic tool for monitoring areas of risk?

Should unexplained variation across a variety of data sources be used as a strategic tool to monitor areas of risk? 


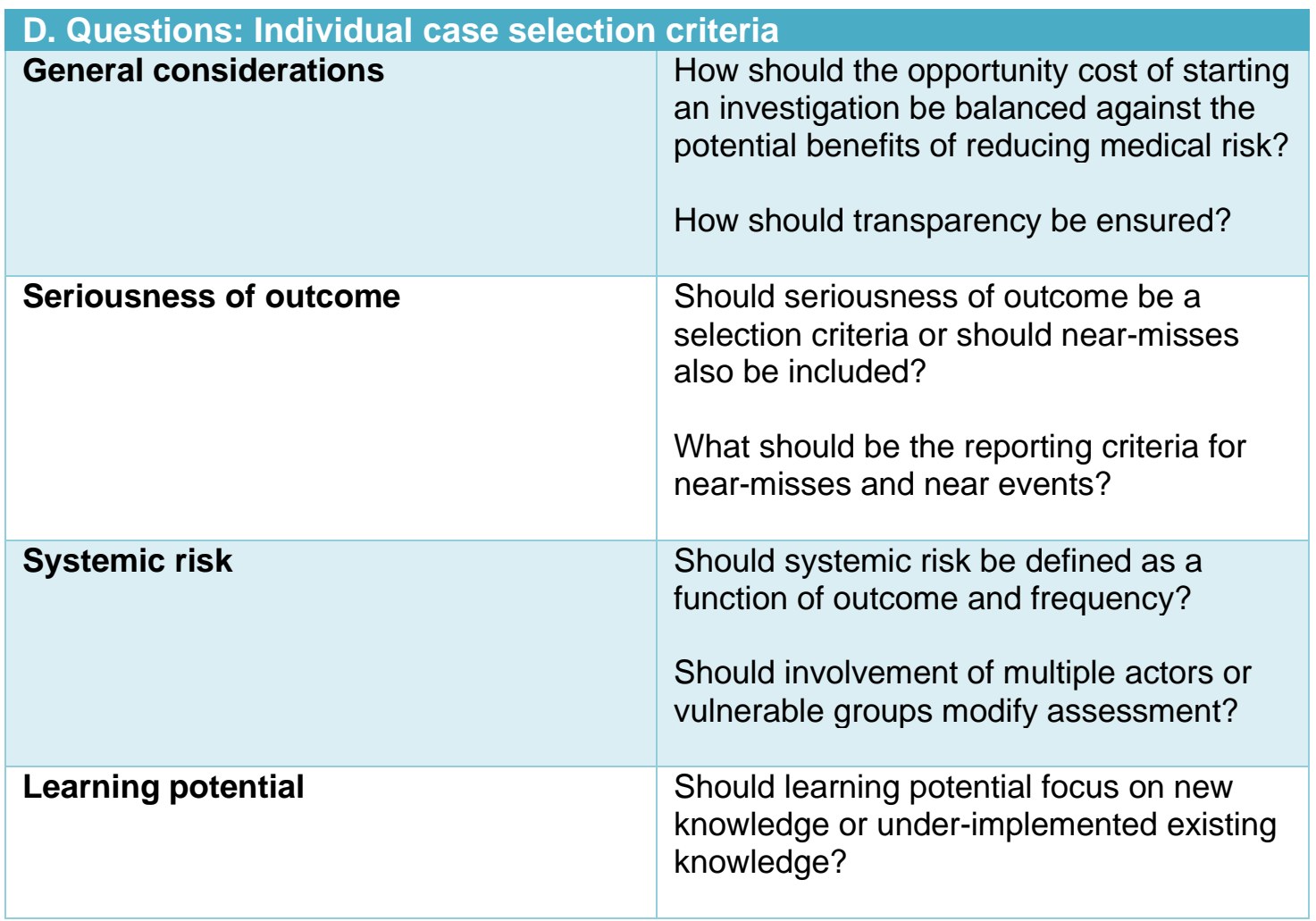




\section{Conclusion}

\subsection{Conclusion and policy implications}

The healthcare system across the world is under increasing strain due to a rapidly aging population with more comorbidities. Healthcare remains a high-risk endeavour and serious adverse events are a consistent challenge. In Norway, there are thousands of serious adverse events annually. Data is lacking from the primary health sector and there is likely considerable underreporting. However, there is currently limited knowledge on how to build a system that is robust enough to reliably identify cases that represent areas of high risk and systemic learning potential. Indeed, the volume of serious adverse events and near-misses far exceed what is possible to investigate on a national level given current resource limitations. This necessitates a strategic approach to setting up new investigative bodies and how these should go about selecting individual cases for investigation.

In response to this gap in knowledge. The following key research question was identified: What is an effective framework to strategically select nationally reported serious adverse events in healthcare for investigation to improve patient safety?

This study is based on literature reviews and interviews with senior officials from key stakeholder organizations in Norway and the UK. The output is a novel theoretical framework to help guide policy makers address strategic issues. The framework identifies four key themes:

(1) Governance, independence, and role

(2) Monitoring trends and risks

(3) Building a strategic portfolio

(4) Individual case selection criteria

For each of these themes, several key questions were identified that policy makers should address when setting up a new patient safety investigative body. This process may both be viewed as a cascading sequence and a cyclical process.

Ultimately, there should be governance structures in place to ensure independence as well as a clear role within the national patient safety landscape. Risk and trend monitoring could also be placed at a centralized emerging risks analysis unit looking across a broad range of sources including adverse events, quality indicators, operational data and health registries. Indeed, continuous monitoring is necessary to counteract underreporting and biases. To ensure a broad coverage of the health sector as well as addressing deeper systemic risks vulnerable groups such as elderly, psychiatric patients and other selected groups may be prioritized. Finally, individual cases should be selected as transparently as possible considering systemic risk as well as learning potential as key criteria. 
Indeed, it is important to note that a new national health safety investigation body should be viewed in the overall context including socio-economic factors, regulatory landscape, the healthcare system as well as the risk landscape. Indeed, the case selection mechanism should be adapted to local needs. Ultimately, selection of adverse events for investigation should form part of a larger patient safety strategy. Hopefully, this framework may serve as a template to allow for other countries to develop effective selections strategies that are suited to local needs.

\subsection{Limitations and future research}

The models and findings are largely based on data gathered from literature and from interviews of senior officials in key stakeholder organizations. The findings may reflect biases held by the interviewed individuals and important issues may have been overlooked. Furthermore, there is limited existing research that addresses this research question, and important considerations may therefore have escaped the discussion at hand. Future research could further develop, operationalize and/or validate the proposed theoretical framework by testing it across various countries and healthcare settings. The model could be further adapted to local needs for both developed and developing countries. 


\section{Bibliography}

Conradi, K., 2019. Changing the safety landscape page 24.

Edmondson, A.C., 2004. Learning from failure in health care: frequent opportunities, pervasive barriers. BMJ Quality \& Safety 13, ii3-ii9. https://doi.org/10.1136/qshc.2003.009597

Fact Sheet: Aging in the United States - Population Reference Bureau, 2019. URL https://www.prb.org/aging-unitedstates-fact-sheet/ (accessed 1.20.21).

Fultron Aviaton Corporation: Improving Stakeholder Engagement, n.d. https://doi.org/10.17226/24756

General Data Protection Regulation, 2021. . Wikipedia.

Health Supervisory Board: Do Inspections improve quality?, 2021.

Hillestad, R., Bigelow, J., Bower, A., Girosi, F., Meili, R., Scoville, R., Taylor, R., 2005. Can Electronic Medical Record Systems Transform Health Care? Potential Health Benefits, Savings, And Costs. Health Affairs 24, 1103-1117. https://doi.org/10.1377/hlthaff.24.5.1103

How we decide to investigate [WWW Document], 11:26:08.775060+00:00. . Healthcare Safety Investigation Branch. URL https://www.hsib.org.uk/clinical-staff/how-we-decide-toinvestigate/ (accessed 2.6.21).

Individual Project CJBS: Informants 1-6, 2021.

Macrae, C., 2016. The problem with incident reporting. BMJ Qual Saf 25, 71-75. https://doi.org/10.1136/bmjqs-2015-004732

Macrae, C., Vincent, C., 2014. Learning from failure: the need for independent safety investigation in healthcare. J R Soc Med 107, 439-443. https://doi.org/10.1177/0141076814555939

Mitchell, M., Kan, L., 2019. Digital Technology and the Future of Health Systems. Health Syst Reform 5, 113-120. https://doi.org/10.1080/23288604.2019.1583040

Moran, A.M.\& J.W., 2018. Decisions, decisions... the RVCE Prioritization Matrix [WWW Document]. Process Excellence Network. URL https://www.processexcellencenetwork.com/lean-six-sigmabusiness-performance/articles/decisions-decisions-the-rvce-prioritization-matrix (accessed 4.5.21).

New bill to improve patient safety [WWW Document], 2017. . GOV.UK. URL https://www.gov.uk/government/news/new-bill-to-improve-patient-safety (accessed 2.6.21).

Norwegian Government Policy Paper: NOU 2015: 11 [WWW Document], 2015. . Regjeringen.no. URL https://www.regjeringen.no/no/dokumenter/nou-2015-11/id2459861/ (accessed 2.6.21).

Norwegian Health Supervision Board: Annual report [WWW Document], 2020. . Helsetilsynet. URL https://www.helsetilsynet.no/publikasjoner/arsrapporter/ (accessed 1.20.21).

Norwegian Law: Act of Health Care Supervision [WWW Document], 2021. URL https://lovdata.no/dokument/NL/lov/2017-12-15-107 (accessed 4.5.21). 
Norwegian Regulation: Health, environment and safety in agencies (Internal control) [WWW Document], 2019. URL https://lovdata.no/dokument/SF/forskrift/1996-12-06-1127 (accessed 2.6.21).

Norwegian Regulation: Mangement and Quality Improvement in the healthcare sector [WWW Document], 2019. URL https://lovdata.no/dokument/LTI/forskrift/2016-10-28-1250 (accessed 2.6.21).

Norwegian Statistical Bureau: A historic change [WWW Document], 2020. . ssb.no. URL https://www.ssb.no/befolkning/artikler-og-publikasjoner/et-historisk-skifte-flere-eldre-enn (accessed 1.20.21).

Regulations for service providers and managers | Care Quality Commission [WWW Document], n.d. URL https://www.cqc.org.uk/guidance-providers/regulations-enforcement/regulations-serviceproviders-managers (accessed 2.6.21).

Risk management framework, 2020. . Wikipedia.

Rudi, H.M., n.d. Supervision aims to improve quality and safety - what are the criteria? . november 24.

The Act of the Norwegian Healthcare Investigation Board - Lovdata [WWW Document], 2017. URL https://lovdata.no/dokument/NL/lov/2017-06-16$56 ? \mathrm{q}=$ statens \%20unders\%C3\%B8kelseskommisjon (accessed 2.6.21).

The Norwegian Health Directorate: Patient Safety Programme [WWW Document], 2021. . Pasientsikkerhetsprogrammet. URL https://pasientsikkerhetsprogrammet.no/ (accessed 1.20.21).

The Norwegian Healthcare Investigation Board: Mental health of children and adolescents one year into the pandemic, 2021.

The Norwegian Healthcare Investigation Board. Strategy 2.0, 2020.

The Norwegian Patient Safety Programme: Improvement guide [WWW Document], 2021. . Patient safety programme. URL

https://pasientsikkerhetsprogrammet.no/forbedringskunnskap/forbedringsarbeid/her-kan-dulaste-ned-forbedringsguiden (accessed 2.6.21).

Toy, P., Lowell, C., 2007. TRALI - Definition, mechanisms, incidence and clinical relevance. Best Pract Res Clin Anaesthesiol 21, 183-193. https://doi.org/10.1016/j.bpa.2007.01.003

Wiig, S., Braithwaite, J., Clay-Williams, R., 2020. It's time to step it up. Why safety investigations in healthcare should look more to safety science. International Journal for Quality in Health Care 32, 281-284. https://doi.org/10.1093/intqhe/mzaa013

Wiig, S., Macrae, C., 2018. Introducing national healthcare safety investigation bodies. British Journal of Surgery 105, 1710-1712. https://doi.org/10.1002/bjs.11033

Woloshynowych, M., Rogers, S., Taylor-Adams, S., Vincent, C., 2005. The Investigation and Analysis of Critical Incidents and Adverse Events in Healthcare. Health technology assessment (Winchester, England) 9, 1-143, iii. https://doi.org/10.3310/hta9190

Wright, T., 2021. Introducing: Strategy Model [WWW Document]. URL https://www.cascade.app/blog/introducing-strategy-models (accessed 4.5.21). 


\section{Appendices}

\subsection{Literature search terms}

Searches were made on Google Scholar and Pubmed.

Search terms that were used included in various combinations:

- National healthcare investigation (body / agency / organization)

- Governance (independence / sanctions / stakeholders)

- Monitoring (risk / trends / underreporting)

- Portfolio (adverse events / vulnerable group)

- Selection and (outcome / systemic risk / learning potential)

Although these search terms yield many results, only few are directly related to the research question. The papers were then assessed on a qualitative basis for relevance to the specific research question. A selection was therefore made for key literature.

See detailed results in Table A-1 and A-2.

Table A-1. Results from literature review

\begin{tabular}{|c|c|}
\hline Search theme & Key literature \\
\hline $\begin{array}{c}\text { Role of } \\
\text { governance }\end{array}$ & $\begin{array}{l}\text { - McCrae et al (2014) (Macrae and Vincent, } \\
\text { 2014) } \\
\text { - Wiig et al (2018) (Wiig and Macrae, 2018) } \\
\text { - Conradi et al (2017) (Conradi, 2019) } \\
\text { - Futron Aviation corporation (2017) (Fultron } \\
\text { Aviaton Corporation: Improving Stakeholder } \\
\text { Engagement, n.d.) }\end{array}$ \\
\hline Risk monitoring & $\begin{array}{ll}\text { - } & \text { McCrae et al (2015) (Macrae, 2016) } \\
\text { - } & \text { Woloshynowych et al (2005) } \\
& \text { (Woloshynowych et al., 2005) } \\
\text { - } & \text { Hillestad et al (2005) (Hillestad et al., 2005) }\end{array}$ \\
\hline $\begin{array}{l}\text { Strategic } \\
\text { portfolio }\end{array}$ & - Wiig et al (2020) (Wiig et al., 2020) \\
\hline Selection criteria & $\begin{array}{l}\text { - Edmondson (2004) (Edmondson, 2004) } \\
\text { - Healthcare Safety Investigation Branch } \\
\text { (2021) ("How we decide to investigate," } \\
11: 26: 08.775060+00: 00)\end{array}$ \\
\hline
\end{tabular}


Table A-2. Health policy documents (Norway and United Kingdom)

\section{Key regulatory document}

- Internal Control Regulation ("Norwegian Regulation: Health, environment and safety in agencies (Internal control)," 2019)

- Regulation for management and quality improvement in healthcare services ("Norwegian Regulation: Mangement and Quality Improvement in the healthcare sector," 2019)

- Quality improvement guide ("The Norwegian Patient Safety Programme:

Norway Improvement guide," 2021)

- Health inspections to improve patient safety in healthcare services ("Health Supervisory Board: Do Inspections improve quality?," 2021; Rudi, n.d.)

- Prevention and follow-up of serious adverse events in the healthcare system (“NOU 2015," 2015)

- Law for national healthcare investigation board("The Act of the Norwegian Healthcare Investigation Board - Lovdata," 2017)

- Regulation for service providers and managers ("Regulations for service providers and managers | Care Quality Commission," n.d.)

- New bill to improve patient safety ("New bill to improve patient safety," 2017) 